\title{
The Use of Montmorillonite Clays as Reinforcing Fillers for Dental Adhesives
}

\author{
Lívia Rodrigues de Menezes ${ }^{a}$, Emerson Oliveira da Silva ${ }^{a *}$ \\ ${ }^{a}$ Instituto de Macromoléculas Professora Eloisa Mano, Universidade Federal do Rio de Janeiro- \\ UFRJ, 21941-970, Rio de Janeiro, RJ, Brazil
}

Received: June 24, 2015; Revised: November 12, 2015; Accepted: December 15, 2015

\begin{abstract}
The aim of this study was to obtaining an adhesive made of dimethacrylate copolymer and clay particles in different concentrations. The samples were prepared by light curing and were evaluated by XRD, FTIR and TGA as well as by measuring flexural strength, elasticity modulus and tensile resistance. The XRD and the mechanical test results indicated that the system with $0.2 \%$ clay is exfoliated, while the highest concentrations showed the agglomeration of these clays. FTIR was used to determine the conversion, and showed that use of clays particles are unable to significantly alter the polymerization until $1.0 \%$. However, for the group containing $1.5 \%$, there was a decline in this index. In the thermogravimetric analysis, only the groups with $0.2 \%$ of clays showed increased thermal resistance. In conclusion, the incorporation of clay at $0.2 \%$ concentration produces a well-dispersed system and can be applied as a dental adhesive.
\end{abstract}

Keywords: Dental adhesives, Nanoclays, Dispersion, Mechanical properties

\section{Introduction}

Adhesives are widely used in restorative dentistry due to their simplicity of use. Bonding is a process basically involving the selective substitution of tooth minerals for a resin. In this technique, the micropores created by the acid etching are filled with a fluid resin ${ }^{1}$ which polymerizes in situ, leading to a micro-mechanical interlock between the dental adhesive and the tooth structure. In this way, these adhesives can reduce the weakening of the tooth structure, making them a good choice to replace the use of macro-mechanical retentions. ${ }^{2}$

These materials basically consist of a polymeric matrix formed by methacrylate monomers, with solvents and a photo-initiator system..$^{3-5}$ Nowadays, inorganic particles are used in their formulation because this improves some physical and mechanical properties. ${ }^{6.7}$ Nanoparticles are widely used as reinforcing fillers in composites, since they have a strong impact on properties when incorporated in smaller amounts in comparison with macro/micro fillers. ${ }^{8,9}$ Besides this, because of their small sizes, nanoparticles are able to penetrate into the tooth micropores, providing a bond layer with improved properties. ${ }^{6,10}$

Clay-polymer systems can show improvement of many properties of polymeric matrixes, such as elastic modulus, flexural and tensile properties and heat resistance. Clay systems have many possible morphologies, which include: (1) agglomerated particles, where the layers remain joined and polymer chains only interact with their surface; (2) intercalated, when the polymer chains are between the clay platelets; and (3) exfoliated, when the silicate platelets are isotropically dispersed in the polymeric matrix. ${ }^{11,12}$

Although some researchers have reported the possible use of nanofillers in dental adhesives, their use remains a

*e-mail: eos@ima.ufrj.br challenge due to the still limited number of fillers used for this purpose. ${ }^{6}$ Therefore, the aim of this study was to investigate the effect of the concentration and type of organomodified montmorillonite clays in the adhesion layer on the mechanical properties of dental adhesives.

\section{Materials and Methods}

In this study was used a standardized matrix (Table 1) containing bisphenol A-glycidyl methacrylate (BisGMA), urethane dimethacrylate (UDMA), 2-hydroxylethyl methacrylate (HEMA) and triethylene glycol dimethacrylate (TEGDMA) associated with a camphorquinone (CQ) system as photoinitiator. All systems also contained a standardized quantity of solvent ( $40 \%$ ethanol). It were used two commercial organoclays obtained from Laviosa Chimica Mineraria S.p.A: Dellite ${ }^{\circledast}$ $67 \mathrm{G}$ and Viscogel ${ }^{\circledR} \mathrm{B} 8$. Both of them have been modified by Bis(Hydrogenated Tallow Alkyl) Dimethyl Ammonium. But Dellite ${ }^{\circledR} 67 \mathrm{G}$ has high content of modifier, and Viscogel ${ }^{\circledR}$ B8 has $10 \%$ of 2 -propanol. The mixtures were prepared with $0.2,0.5,1.0$ and $1.5 \% \mathrm{~m} / \mathrm{m}$ of clay on the systems.

\subsection{Adhesive preparation}

The fillers of each group were mixed with matrix using a closed mixing system (IKA Ultra Turrax Tube Drive ST20 Werke, Staufen, Germany). First, the chosen amount of clay was dispersed in ethanol under stirring for 24 hours to allow swelling. After this step, the polymer matrix was added to the clay/ethanol dispersion, without addition of the photopolymerization system. Then the systems were mixed for 30 minutes at $6000 \mathrm{rpm}$ at a controlled temperature of 21 ${ }^{\circ} \mathrm{C}$. After this, the photopolymerization system was added, and the mixture was stirred for 3 minutes at 3000 rpm under controlled light to obtain the adhesive systems. 


\subsection{Degree of conversion}

The degree of conversion of the dental adhesives was determined by Fourier-transform infrared spectroscopy (FTIR: Spectrum 100 Optica; PerkinElmer, MA, USA), containing an attenuated total reflectance apparatus with a ZnSe crystal (Pike Technologies, Madison, WI, USA). The test was performed on the polymerized and non-polymerized samples and the degree of conversion was calculated using the band ratios of $1638 \mathrm{~cm}^{-1}$ and $1608 \mathrm{~cm}^{-1} \cdot{ }^{13,14}$

\subsection{X-ray diffraction}

The exfoliation of nanoclay particles in dental adhesive samples was analyzed by $\mathrm{X}$-ray diffraction (XRD). The tests were performed with $\mathrm{CuK} \alpha$ radiation $(\lambda=1.5418 \AA), 40 \mathrm{kV}$, $20 \mathrm{~mA}$, in a Rigaku Ultima IV X-ray diffractometer, over the $2 \theta$ range of $2-80^{\circ}$ at room temperature with a step size of $0.02^{\circ}$. However, only the $2 \theta$ range of $2-8^{\circ}$ was shown because the exfoliation of the clay is available only in that range.

\subsection{Thermogravimetric analysis}

The thermogravimetric analysis (TGA) was performed with a TA Instruments Q50 analyzer. Samples of approximately $15 \mathrm{mg}$ were heated from 30 to $700{ }^{\circ} \mathrm{C}$ under a nitrogen flow, with a heating rate of $10^{\circ} \mathrm{C} / \mathrm{min}$.

\subsection{Measurement of flexural strength and elastic modulus}

The three-point bending method was performed in order to evaluate the flexural strength and the elastic modulus of the composites using a universal testing machine (Instron 4411 Model 4484; Canton; Massachusetts, USA). Each composite was placed in a silicon rubber mold $(7 \mathrm{~mm} \mathrm{x}$ $1 \mathrm{~mm} \times 1 \mathrm{~mm})$. Firstly, a gentle airflow was applied for 40 seconds to evaporate the solvent, and, then, the material was light-cured (Radii Cal, 1200mW/cm2, SDI, Bayswater, Australia) through a glass microscope slide for 60 seconds. The polymerized samples were subjected to the three-point

Table 1. Standardized composition of dental adhesives

\begin{tabular}{cc}
\hline Component & (\%) \\
\hline Bis-GMA & 22 \\
UDMA & 13 \\
TEGDMA & 13.5 \\
HEMA & 10 \\
Ethanol & 40 \\
Camphorquinone & 0.7 \\
2- (dimethylamino) ethyl methacrylate (DMAEMA) & 0.5 \\
Butyl hydroxytoluene (BHT) & 0.3 \\
\hline
\end{tabular}

bending after 24 hours of dark and dry storage $\left(37^{\circ} \mathrm{C}\right)$. Flexural strength test apparatus of two rods ( $2 \mathrm{~mm}$ in diameter), mounted parallel with $20 \pm 0,1 \mathrm{~mm}$ between centers, and a third rod ( $2 \mathrm{~mm}$ in diameter) centered between, and parallel to the other two, so that the three rods in combination can be used to give a three-point loading to the specimen, was appropriately calibrated, to provide a constant cross-head speed of $(0,75 \pm 0,25) \mathrm{mm} / \mathrm{min}$ with a rate of loading of $(50 \pm 16) \mathrm{N} / \mathrm{min}$. In order to minimize the statically error, a set of ten samples was tested for each composite evaluated.

\subsection{Measurement of Microtensile Strength}

The microtensile strength test was performed in order to evaluate the cohesive strength of the composites. Bar shaped samples were performed as previously described before. The polymerized samples were subjected to the microtensile strength test after 24 hours of dark and dry storage $\left(37^{\circ} \mathrm{C}\right)$. The ends of each bar were stocked to the universal testing machine (Instron 4411) with cyanoacrylate glue, and the specimens were loaded in tension until de fracture at a crosshead speed of $0.5 \mathrm{~mm} / \mathrm{min} .{ }^{15,16} \mathrm{In}$ order to minimize the statically error, a set of ten samples was tested for each composite evaluated.

\section{Results}

The degree of conversion values (Table 2) of the adhesives tested were between $74 \%$ and $65 \%$, which is considered normal for these materials. ${ }^{17}$ It was observed that there was no significant reduction on conversion of these materials with the addition of up to $1.0 \%$ of nanoclay. However, for the group containing $1.5 \%$, a decrease was observed.

The XRD analysis is very useful to evaluate the dispersion of the nanoclay when incorporated into a polymeric matrix and to determine the basal spacing. The shift or absence of the $\mathrm{d}(001)$ peak indicates that the basal spacing between the clay lamellae was changed (if shifted) or if the system has become exfoliated. From the diffractograms (Figure 1), the basal spacing was determined by applying Bragg's equation: $\mathrm{n} \lambda=2 \sin \theta$ to the $\mathrm{d}(001)$ peak. The calculations showed that the basal spacing of the Dellite $67 \mathrm{G}$ and Viscogel B8 are $36.8 \AA$ and $31.6 \AA$, respectively and the values of basal spacing of all systems can be seen in table 3 .

The diffractograms showed that the $\mathrm{d}(001)$ peak of the systems with $1.5 \%$ of both clays and $1.0 \%$ of Viscogel B8 remained in a similar position as the pure clay. In other words, the basal space do not changed. This indicates the generation of agglomerate systems.. In groups containing $1.0 \%$ Dellite $67 \mathrm{G}$ filler and $0.5 \%$ of both clays, in turn, this peak shifted to lower angles, showing an increase in the interlayer distance, indicating the formation of intercalated systems.

Table 2. Mean and standard deviation of conversion degree (\%) of dental adhesives

\begin{tabular}{cccccc}
\hline \multirow{2}{*}{ Fillers } & \multicolumn{5}{c}{ Degree of conversion (\%) } \\
\cline { 2 - 5 } & $\mathbf{0 \%}$ & $\mathbf{0 . 2 \%}$ & $\mathbf{0 . 5} \%$ & $\mathbf{1 . 0 \%}$ & $\mathbf{1 . 5 \%}$ \\
\hline Viscogel B8 & $74.9 \pm 3.4 \mathrm{Aa}^{*}$ & $73.6 \pm 2.9 \mathrm{Aa}$ & $72.7 \pm 3.3 \mathrm{Aa}$ & $75.1 \pm 3.7 \mathrm{Aa}$ & $63.2 \pm 2.2 \mathrm{Bb}$ \\
Dellite $67 \mathrm{G}$ & $74.9 \pm 4.2 \mathrm{Aa}$ & $74.3 \pm 3.1 \mathrm{Aa}$ & $71.9 \pm 2.6 \mathrm{Aa}$ & $74.8 \pm 4.1 \mathrm{Aa}$ & $62.7 \pm 2.5 \mathrm{Bb}$ \\
\hline
\end{tabular}

* Means followed by different letters (uppercase in columns and lowercase in rows) differ from each other ( $\leq 0.05$ ) 
The $d(001)$ peak disappeared at the lowest nanofiller concentrations $(0.2 \%)$ of both systems and in the system with $0.5 \%$ Dellite $67 \mathrm{G}$. This indicates the exfoliation of clays on these systems or, even, an increase in spacing between platelets greater than the limit of detection $(44 \AA)$ of the diffratometer. Therefore, a more expanded configuration of the intercalated system was not clearly distinguishable from the exfoliated morphology.

Figure 2 shows the thermogravimetric behavior of the dental adhesives with different clay concentrations. In all systems can be observed an initial loss of mass between $80-200{ }^{\circ} \mathrm{C}$ and most likely attributed to the loss of residual ethanol and low-molecular weight monomers, like HEMA. The presence of residual solvent was expected, since these samples were air dried to simulate their clinical application (Figure 3 ). The second $\left(\mathrm{T}_{\text {peak }}\right.$ approximately $360{ }^{\circ} \mathrm{C}$ ), third $\left(\mathrm{T}_{\text {peak }}\right.$ approximately $380^{\circ} \mathrm{C}$ ) and fourth losses of mass ( $\mathrm{T}_{\text {peak }}$ approximately $400^{\circ} \mathrm{C}$ ) can be assigned to the decomposition of higher molecular-weight structures, comprising the chain areas formed more intensely by flexible components such as HEMA and TEGDMA for the second and third stages, along with areas of greater rigidity in the fourth stage, with higher prevalence of BIS-GMA and UDMA. ${ }^{18}$

Regarding thermal resistance, the groups containing $0.2 \%$ filler load showed an increase in thermal resistance while the other concentrations showed no significant changes in this property. This behavior can be explained based on the dispersion of layered nanofillers, since the group with $0.2 \%$, possibly, has an exfoliated morphology.

According to the results observed in the graphs of elastic modulus and tensile strength (Figures 4 and 5, respectively), the change of properties caused by the nanofillers had the maximum change occurred at low clay concentration $(0.2 \%)$, after which point the mechanical properties declined with increasing concentration. Also it can be noted that for the same load concentrations, Dellite $67 \mathrm{G}$ clay showed better results than Viscogel B8, (Table 4), which can be explained by better dispersion of the clay, as indicated by XRD.

The flexural strength (Figure 6), in turn, did not change as much between the samples with $0.2 \%$ of both clay nanofillers. In these cases, the samples with $0.2 \%$ showed similar statistical behavior to the groups with $0.5 \%$ and $1.0 \%$.
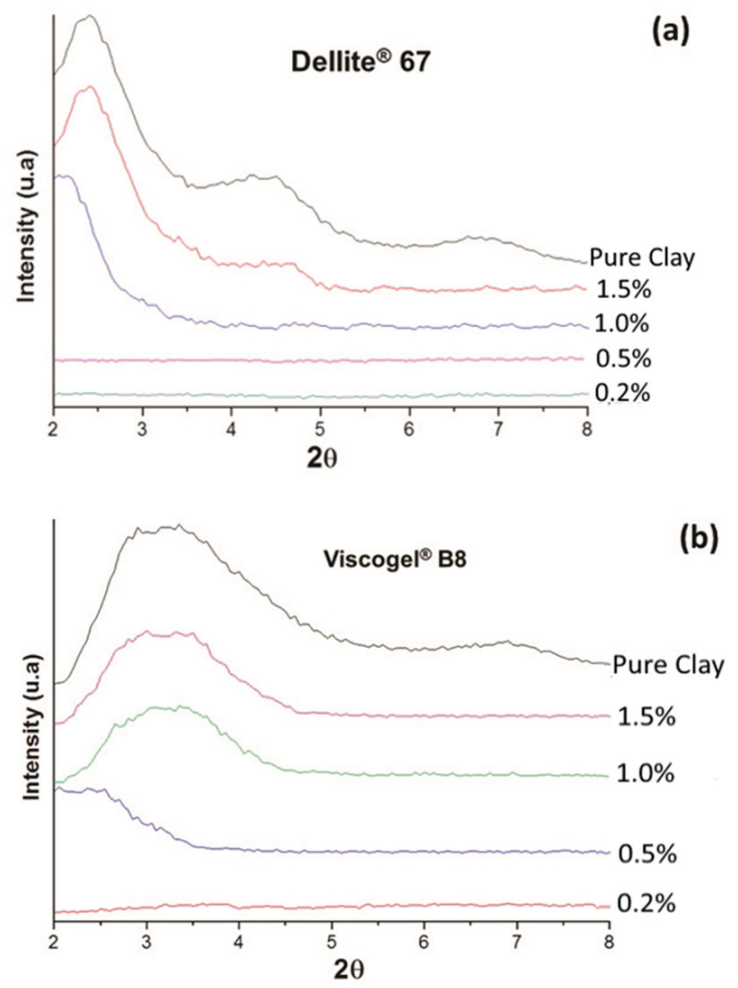

Figure 1. Diffractograms of adhesives containing varying concentrations of the clays Dellite 67G (a) and (b) Viscogel B8

Table 3. Basal spacing values of pure clays and of adhesives containing varying concentrations of the clays

\begin{tabular}{cccccc}
\hline \multirow{2}{*}{ Fillers } & \multicolumn{5}{c}{ Basal spacing values $(\AA)$} \\
\cline { 2 - 6 } & Pure Clays & $\mathbf{0 . 2 \%}$ & $\mathbf{0 . 5 \%}$ & $\mathbf{1 . 0 \%}$ & $\mathbf{1 . 5 \%}$ \\
\hline Viscogel B8 & 31.6 & - & 38.2 & 36.2 & 31.6 \\
Dellite 67G & 36.8 & - & - & 42.3 & 36.8 \\
\hline
\end{tabular}

Table 4. Mean and standard deviation of flexural resistance, elastic modulus and tensile strength of dental adhesives

\begin{tabular}{cccc}
\hline Material & Flexural resistance (MPa) & $\begin{array}{c}\text { Elastic modulus } \\
(\mathbf{G P a})\end{array}$ & $\begin{array}{c}\text { Tensile strength } \\
(\mathbf{M P a})\end{array}$ \\
\hline Pure Adhesive & $49.9 \pm 4.8$ & $0.54 \pm 0.07$ & $19.5 \pm 2.1$ \\
Adhesive 0.2\% Dellite 67G & $82.5 \pm 3.9$ & $1.12 \pm 0.1$ & $28.7 \pm 1.3$ \\
Adhesive 0.5\% Dellite 67G & $79.4 \pm 3.4$ & $0.97 \pm 0.08$ & $26.8 \pm 2.2$ \\
Adhesive 1.0\% Dellite 67G & $73.5 \pm 2.5$ & $0.82 \pm 0.04$ & $25.4 \pm 1.3$ \\
Adhesive 1.5\% Dellite 67G & $57.6 \pm 2.3$ & $0.59 \pm 0.03$ & $18.1 \pm 2.1$ \\
Adhesive 0.2\% Viscogel B8 & $76.3 \pm 3.4$ & $0.96 \pm 0.08$ & $27.7 \pm 1.5$ \\
Adhesive 0.5\% Viscogel B8 & $75.2 \pm 2.6$ & $0.76 \pm 0.06$ & $25.1 \pm 2.4$ \\
Adhesive 1.0\% Viscogel B8 & $70.4 \pm 2.3$ & $0.63 \pm 0.05$ & $22.6 \pm 1.6$ \\
Adhesive 1.5\% Viscogel B8 & $56.2 \pm 3.1$ & $0.53 \pm 0.07$ & $17.5 \pm 2.4$ \\
\hline
\end{tabular}



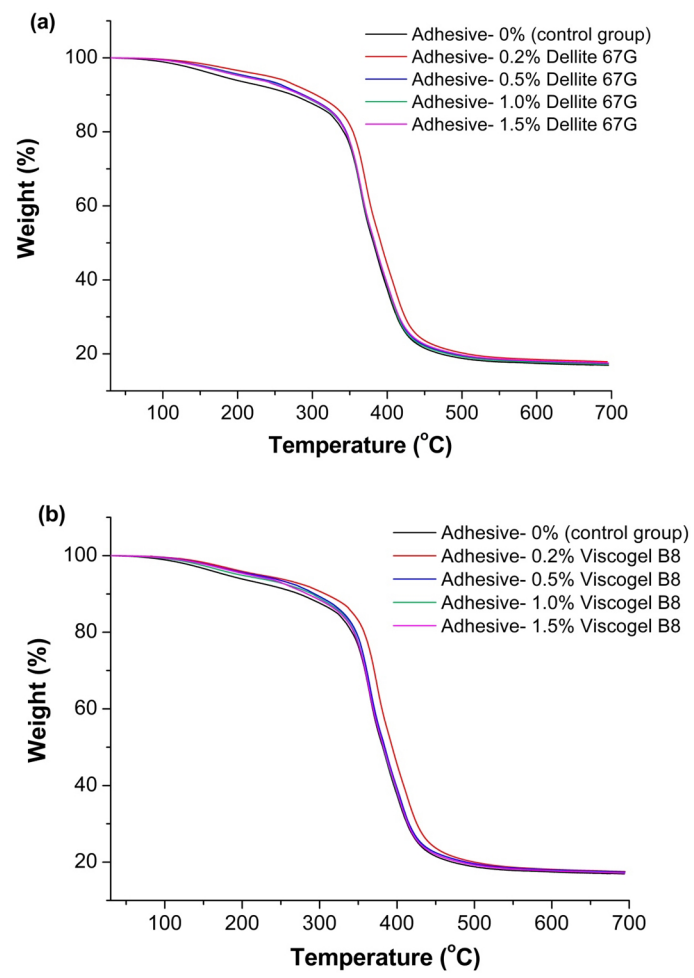

Figure 2. Curves of the thermogravimetric analysis of adhesives containing varying concentrations of the clays Dellite $67 \mathrm{G}$ (a) and Viscogel B8 (b)
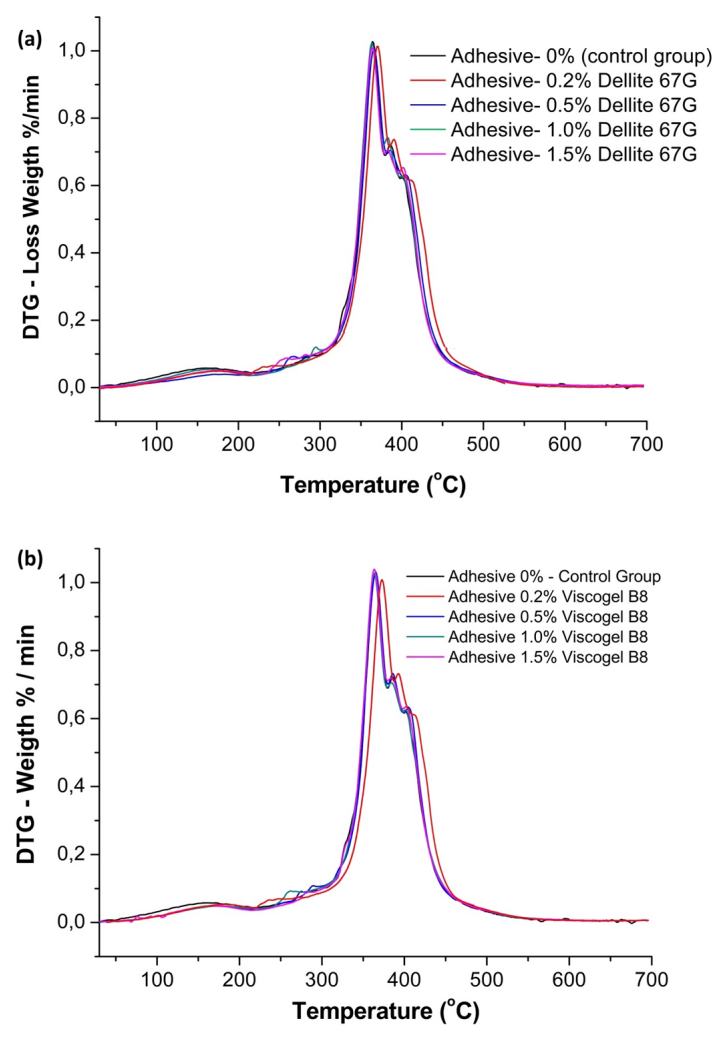

Figure 3. DTG of adhesives containing varying concentrations of the clays Dellite 67G (a) and Viscogel B8 (b)

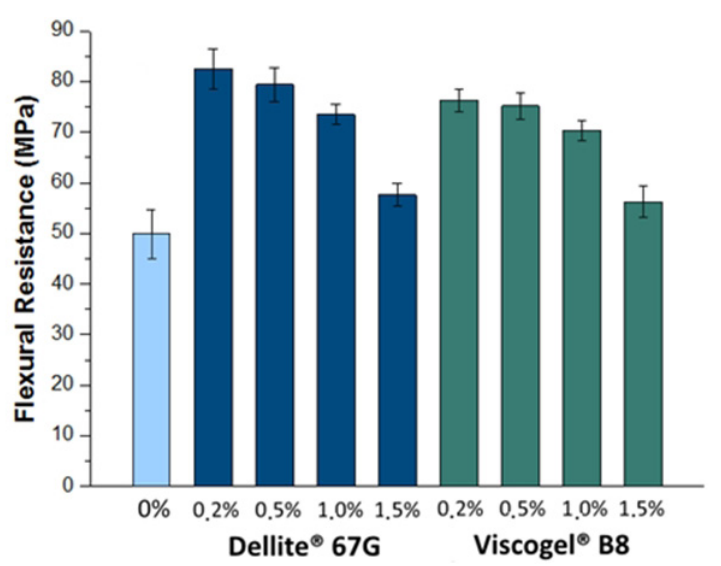

Figure 4. Flexural resistance of the dental adhesives containing different percentages of nanofillers

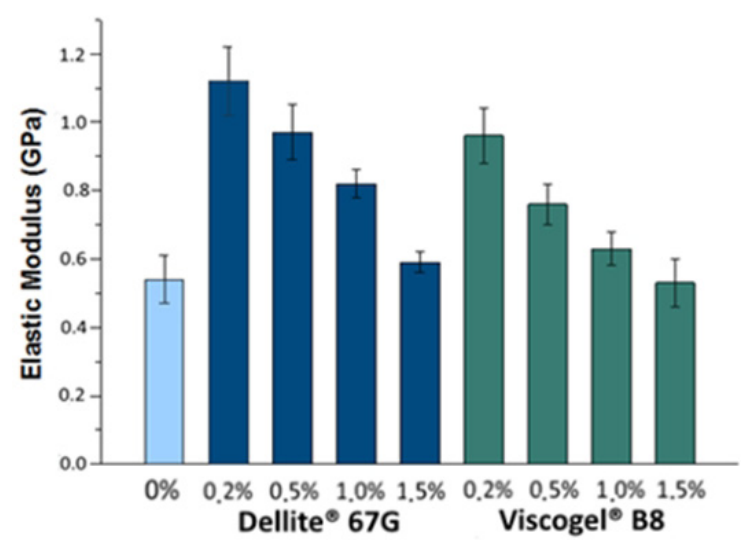

Figure 5. Elastic modulus of the dental adhesives containing different percentages of nanofillers

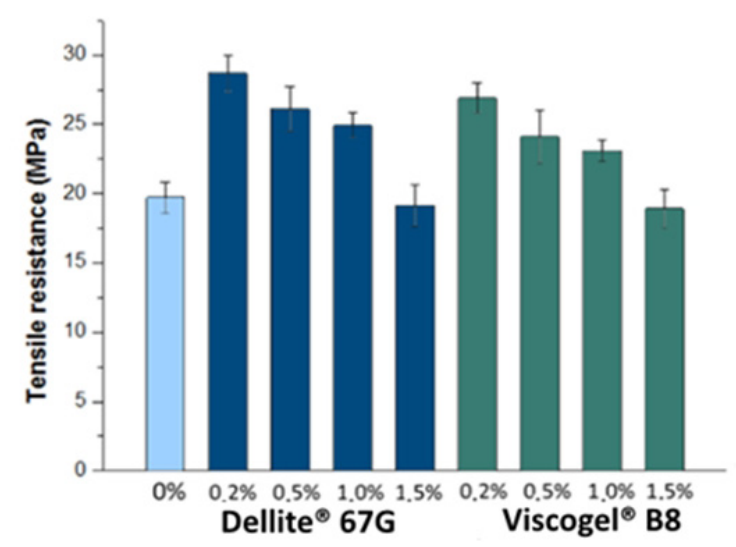

Figure 6. Tensile strength of the dental adhesives containing different percentages of nanofillers

\section{Discussion}

The degree of conversion is an important parameter to judge the effectiveness of the adhesion layer. Low degree of conversion values lead to lower elastic modulus values, which reduce the adhesion strength. No changes in the degree of conversion were observed in the material up to $1.0 \%$ of clay 
content, indicating that until this concentration, the particles are not capable of altering light transmission through the material and did not greatly alter the viscosity of the systems. Many fillers have previously been reported to increase the viscosity of the system, which restricts the movement of their constituent components during the polymerization process. ${ }^{19}$ However, the reduction of conversion at the highest concentration (1.5\%) of these fillers may be due to the low quality of dispersion in the material.In this case, they act as microfillers, functioning as points of absorption and scattering of light, making the light photoinitiation process ineffective for camphorquinone stimulus, and consequently reducing the formation of radical species. ${ }^{17}$

According to the results of XRD and mechanical tests, Dellite $67 \mathrm{G}$ showed better dispersion in the systems than Viscogel B8. This finding can be explained by the fact that Dellite $67 \mathrm{G}$ has a higher basal distance, facilitating the entry of polymer chains between the platelets, and consequently forming systems with improved dispersion with lower concentration of these particles. Moreover, there are some differences between the chemical composition of both clays that affect the interaction between clay and polymer. First of all, as the Dellite ${ }^{\circledR} 67 \mathrm{G}$ has a higher content of organomodifier, the interaction with the polymer matrix is stronger than with Viscogel ${ }^{\circledR}$ B8. In second place, Viscogel ${ }^{\circledR}$ B8 clay was modifier with $10 \%$ of 2-propanol, a polar compound, whose effect is decrease the interaction with the polymer matrix (an apolar material).

It is known that the incorporation of nanoclay in a polymer matrix increases the mechanical properties, particularly the elastic modulus, of systems when the particles have good distribution and dispersion..$^{20}$ The greater improvement of the properties at $0.2 \%$ can be explained by the dispersion of the clay platelets. This dispersion causes a higher gain in surface area of these particles, thus producing a larger polymer/nanofiller interfacial area, ${ }^{21-23}$ which enables most of the atoms on the surface to participate in the interaction between the phases, facilitating the transmission of forces between them and increasing the strengthening effect. This behavior is similar to that observed in other nanofillers. ${ }^{10,24,25}$ The change in mechanical properties can be related to the dispersal of the nanoclays in the system, as supported by the XRD results. The mechanical properties of the systems with $0.2 \%$ clay concentration, due to their possibly exfoliated configuration, changed more than in the other systems, particularly the elastic modulus, a parameter which many authors consider an indirect way to measure these fillers' exfoliation..$^{20,26}$

In the same way, although a d(001) peak did not appear in the materials with $0.5 \%$ Dellite $67 \mathrm{G}$, based on the mechanical results it can be postulated that the dispersion was poorer than in the samples with $0.2 \%$ of the same clay, since with increasing concentration of loads there was no increase in the mechanical properties. If both systems have similar dispersions, an increase in the nanoparticle percentage would mean a higher interfacial area between the polymer and nanofiller due to the larger number of particles in the system. This would lead to more satisfactory dissipation of stresses and better mechanical properties, ${ }^{24,25}$ contrary to what was observed in the mechanical tests.

In this case, the increase in concentration caused such a small change in the mechanical aspects of the polymeric matrix that it would not useful as reinforcement. This behavior arises from the agglomeration of these fillers, which initially makes them act as microparticles, but after reaching a particular concentration, they tend to form larger agglomerates that act as fracture points, causing the material's failure when subjected to mechanical stress. ${ }^{10,27,28}$

Based on the results can be stipulated that the groups containing a lower concentrations of both clays $(0.2 \%)$, will have, when applied to the tooth structure, the highest bond strength in the short and long term, once that these materials exhibit higher microtensile indicating a greater cohesive strength, which reflects in obtaining a bonding interface with less prone to breakage and detachment of the tooth surface. ${ }^{29}$

Likewise, it can be noted that these groups had higher elastic modulus which indicates the increased rigidity of these adhesives systems. The presence of these polymer systems in a more rigid conformation lead to a less tendency of water sorption, since the reduced flexibility of the polymer networks generates a physical obstacle to the passive diffusion of the solvent through the material. ${ }^{30}$ Thus, once the sorption is the primarily responsible for the mechanical strength loss of the adhesive systems because its represent the first stage of degradation of these interfaces by hydrolysis, ${ }^{31,32}$ or because the water acts as a plasticizer of these materials, ${ }^{18,33}$ the obtaining of these systems with greater rigidity reflects on a larger adhesive stability.

The addition of nanoclays in polymers can improve their thermal resistance. This has been demonstrated for clay nanocomposites in various polymer matrixes, ${ }^{34,35}$ but it is dependent of the particle dispersion..$^{34,36,37}$ Therefore, the change observed in the samples with $0.2 \%$ nanoclay is due to the better distribution of these particles in the system. The increase in the temperature required for weight loss in the groups with lower clay concentrations indicates that these systems are exfoliated, corroborating to the diffraction and mechanical results. This fact can be attributed to the ability of layered structures to reduce the flow of gases within the material, and consequently the heat flow. ${ }^{35,36}$

\section{Conclusions}

The incorporation of low concentrations $(0.2 \%)$ of clay significantly improves the elastic modulus of the standardized matrix without changing the degree of conversion. This means that the nanoparticles do not affect the viscosity and coloration of the medium to the point of hindering irradiation and consequently the start of resin polymerization. Therefore, they can be applied using techniques commonly used in dental practice. This material thus has great potential for use as adhesion systems between dentin and restorative resin. It is known that layered nanoparticles can decrease the permeability of small molecules in a composite, which positively affects the durability of the adhesive system. This is a subject of considerable interest and should be further investigated.

\section{Acknowledgments}

We would like to thank Conselho Nacional de Desenvolvimento Científico e Tecnológico (CNPq) and Coordenação de Aperfeiçoamento de Pessoal de Nível Superior (CAPES) for funding. 


\section{References}

1. Derelioglu SS, Yilmaz Y, Celik P, Carikcioglu B, Keles S. Bond strength and microleakage of self-adhesive and conventional fissure sealants. Dental Materials Journal. 2014;33(4):530-538. DOI: http://doi.org/10.4012/dmj.2013-227

2. Münchow EA, Barros GD de, Alves S, Valente LL, Cava SS, Pivo E, et al. Effect of elastomeric monomers as polymeric matrix of experimental adhesive systems : degree of conversion and bond strength characterization. Applied Adhesion Science. 2014; 2(1):1-9.

3. Van Landuyt K, Snauwaert J, Munck J de, Peumans M, Yoshida Y, Poitevin A, et al. Systematic review of the chemical composition of contemporary dental adhesives. Biomaterials. 2007;28(26):3757-3785. doi:10.1016/j.biomaterials.2007.04.044

4. Souza Junior MH, Carneiro KG, Lobato MF, Souza PA, Góes MF. Adhesive systems : important aspects related to their composition and clinical use. Journal of Applied Oral Science. 2010;18(3):207-214. http://dx.doi.org/10.1590/S167877572010000300002

5. De Munck J, Van Landuyt K, Peumans M, Poitevin A, Lambrechts $\mathrm{P}$, Braem M, et al. A critical review of the durability of adhesion to tooth tissue: methods and results. Journal of Dental Research. 2005;84(2):118-132.

6. Provenzi C, Leitune VC, Collares FM, Trommer R, Bergmann $\mathrm{CP}$, Samuel SM. Interface evaluation of experimental dental adhesives with nanostructured hydroxyapatite incorporation. Applied Adhesion Science. 2014;2(2):1-5.

7. Belli R, Kreppel S, Petschelt A, Hornberger H, Boccaccini AR, Lohbauer U. Strengthening of dental adhesives via particle reinforcement. Jounal of the Mechanical Behaviorof Biomedical Materials. 2014;37:100-108.

8. Sinha Ray S, Okamoto M. Polymer/layered silicate nanocomposites: A review from preparation to processing. Progress in Polymer Science. 2003;28(11):1539-1641. doi:10.1016/j. progpolymsci.2003.08.002

9. Paul DR, Robeson LM. Polymer nanotechnology: Nanocomposites. Polymer. 2008; 49(15):3187-3204.

10. Sadat-Shojai M, Atai M, Nodehi A, Khanlar LN. Hydroxyapatite nanorods as novel fillers for improving the properties of dental adhesives: Synthesis and application. Dental Materials. 2010;26(5):471-482. doi:10.1016/j.dental.2010.01.005

11. Tidjani A, Wilkie CA. Photo-oxidation of polymeric-inorganic nanocomposites: Chemical, thermal stability and fire retardancy investigations. Polymer Degradation and Stability. 2001;74(1):3337. doi:10.1016/S0141-3910(01)00061-1

12. Franco-Urquiza EA, Cailloux J, Santana O, Maspoch ML, Infante JC. The influence of the clay particles on the mechanical properties and fracture behavior of PLA/o-MMT composite films. Advances in Polymer Technology. 2014;34(1). DOI: 10.1002/ adv. 21470

13. Jose P, Sakhamuri S, Sampath V, Sanjeev K, Sekar M. Degree of conversion of two dentin bonding agents with and without a desensitizing agent using fourier transform infrared spectroscopy: An in vitro study. Journal of Conservative Dentistry. 2011;14(3): 302-305.

14. Yazdi FM, Moosavi H, Atai M, Zeynali M. Dentin bond strength and degree of conversion evaluation of experimental selfetch adhesive systems. Journal of Clinical and Experimental Dentistry. 2015;7(2):e243-e249. doi: 10.4317/jced.51842

15. Bosquiroli V, Franco EB, Pereira JC, Navarro MF, Mondelli RF. Polymerization of resin composite with halogen lamp and LED. Revista Gaúcha de Odontologia. 2006;54(2): 129-133.
16. Belli R, Kreppel S, Petschelt A, Hornberger H, Boccaccini AR, Lohbauer, U. Strengthening of dental adhesives via particle reinforcement. Journal of the mechanical Behavior of Biomedical Materials. 2014;37:100-108. doi:10.1016/j.jmbbm.2014.05.007

17. Carreno NL, Oliveira TC, Piva E, Leal FB, Lima GS, Monks MD, Raubach CW, Ogliari FA. YbF 3 / SiO 2 fillers as radiopacifiers in a dental adhesive resin. Nano-Micro Letters. 2012;4(3):189-196.

18. Reis A, Ferreira SQ, Costa TR, Klein-Junior CA, Meier MM, Loguercio AD. Effects of increased exposure times of simplified etch-and-rinse adhesives on the degradation of resin - dentin bonds and quality of the polymer network. European Journal os Oral Sciences. 2010;118(5):502-509. DOI: 10.1111/j.16000722.2010.00759.x

19. Leprince JG, Palin WM, Hadis MA, Devaux J, Leloup G. Progress in dimethacrylate-based dental composite technology and curing efficiency. Dental Materials. 2013;29(2):139-156. doi:10.1016/j.dental.2012.11.005

20. Rezanavaz R, Aghjeh MK. Relationship between the morphology and physico-mechanical properties of polyethylene/clay nanocomposites. IOP Conference Series: Materials Scence and Engineering. 2012;40(1):012047.

21. Najafi N, Heuzey MC, Carreau PJ. Polylactide (PLA)-clay nanocomposites prepared by melt compounding in the presence of a chain extender. Composites Science and Technology. 2012;72(5):608-615. doi:10.1016/j.compscitech.2012.01.005

22. Soares BG, Silva AA, Sollymossy AP, Braga RA, Duchet J. Assessing the nanoscale structure of clay epoxy nanocomposites by tuning the physicochemical and processing conditions. Applied Clay Science. 2013;83-84:244-252. doi:10.1016/j. clay.2013.08.037

23. Yang L, Phua SL, Teo JK, Toh CL, Lau SK, Ma J, Lu X. A biomimetic approach to enhancing interfacial interactions: Polydopamine-coated clay as reinforcement for epoxy resin. ACS Applied Materials Interfaces. 2011;3(8):3026-3032. DOI: 10.1021/am200532j

24. Melo MA, Cheng L, Zhang K, Weir MD, Rodrigues LK, Xu $\mathrm{HH}$, et al. Novel dental adhesives containing nanoparticles of silver and amorphous calcium phosphate. Dental Materials. 2013;29(2):199-210. doi:10.1016/j.dental.2012.10.005

25. Lohbauer U, Wagner A, Belli R, Stoetzel C, Hilpert A, Kurland HD, et al. Zirconia nanoparticles prepared by laser vaporization as fillers for dental adhesives. Acta Biomaterialia. 2010;6(12):4539-4546. doi:10.1016/j.actbio.2010.07.002

26. Chan ML, Lau KT, Wong TT, Ho MP, Hui D. Mechanism of reinforcement in a nanoclay/polymer composite. Composites Part B: Engineering. 2011;42(6):1708-1712. doi:10.1016/j. compositesb.2011.03.011

27. Robert MT, Chandran MS, Jishnu S, Rajeen RS, Mathew $\mathrm{D}$, Sreenivas N, et al. Nanoclay modified silica phenolic composites : mechanical properties and thermal response under simulated atmospheric re-entry conditions. Polymer for Advanced Techonologies. 2015; 26(1):104-109.DOI: 10.1002/ pat.3429

28. Pedrazzoli D, Tuba F, Khumalo VM, Pegoretti A, Karger-Kocsis J. Mechanical and rheological response of polypropylene/ boehmite nanocomposites. Journal of Reinforced Plastics and Composites. 2014;33(3):252-265.

29. Takahashi A, Sato Y, Uno S, Pereira PN, Sano H. Effects of mechanical properties of adhesive resins on bond strength to dentin. Dental Materials. 2002; 18(3): 263-268.

30. Gajewski VE, Pfeifer CS, Fróes-Salgado NR, Boaro LC, Braga RR. Monomers used in resin composites: degree of conversion, mechanical properties and water sorption/solubility. Brazilian 
Dental Journal. 2012;23(5):508-514. http://dx.doi.org/10.1590/ S0103-64402012000500007

31. Tjäderhane L, Nascimento FD, Breschi L, Mazzoni A, Tersariol IL, Geraldeli S, et al. Strategies to prevent hydrolytic degradation of the hybrid layer — a review. Dental Materials. 2013; 29(10): 999-1011. doi:10.1016/j.dental.2013.07.016

32. Feitosa VP, Leme AA, Sauro S, Correr-Sobrinho L, Watson TF, Sinhoreti MA, Correr AB. Hydrolytic degradation of the resin-dentine interface induced by the simulated pulpal pressure, direct and indirect water ageing. Journal of Dentistry. 2012;40(12): 1134-1143. doi:10.1016/j.jdent.2012.09.011

33. Carvalho AO, Carrilho MR, Rueggeberg FA, Ambrosano GM, Giannini M. Bond strength, biaxial flexural strength and flexural modulus of dentin bonding systems exposed to water. International Journal of Adhesion and Adhesives. 2014;49:109-114. doi:10.1016/j.ijadhadh.2013.12.017
34. Zhou Q, Xanthos M. Nanosize and microsize clay effects on the kinetics of the thermal degradation of polylactides. Polymer Degradation and Stability. 2009;94(3):327-338. doi:10.1016/j. polymdegradstab.2008.12.009

35. Yi D, Yang R, Wilkie CA. Full scale nanocomposites: Clay in fire retardant and polymer. Polymer Degradation and Stability. 2014;105:31-41. doi:10.1016/j.polymdegradstab.2014.03.042

36. Pandey P, Mohanty S, Nayak SK. Improved flame retardancy and thermal stability of polymer / clay nanocomposites, with the incorporation of multiwalled carbon nanotube as secondary filler : evaluation of hybrid effect of nanofillers. High Performance Polymers. 2014; 26(7):826-836.

37. Schlemmer D, Angélica RS, Sales MJ. Morphological and thermomechanical characterization of thermoplastic starch/ montmorillonite nanocomposites. Composite Structures. 2010;92(9):2066-2070. doi:10.1016/j.compstruct.2009.10.034 